\title{
Inflammation and type 2 diabetes: from basic science to treatment
}

\author{
Marc Y. Donath ${ }^{1}$
}

Received: 9 May 2019 / Accepted: 17 May 2019 / Published online: 25 June 2019

(C) Springer-Verlag GmbH Germany, part of Springer Nature 2019

Many discoveries in science have the following history: it starts with a controversy, then it becomes common knowledge, followed by a hype, then the first drawbacks appear, and eventually the concept is implemented by perseverant scientists. With respect to the role of the immune system in type 2 diabetes, the controversy lasted several years, which clearly delayed clinical translation. The reasons for the longduration of the controversy include the novelty of the concept and moral aspects. As type 2 diabetes is often perceived as self-inflicted and due to a lack of discipline in life-style behaviour, some specialists of the "innocent" immune type 1 diabetes were reluctant to acknowledge associations between the diseases. As will become apparent to the reader of this issue of the Seminars in Immunopathology, in the meantime, the controversy has past. Particularly convincing is the metaanalysis by Kataria and colleagues, which included 2921 patients with type 2 diabetes treated with an IL-1 antagonist [1]. They show a highly significant reduction in glycated haemoglobin. Importantly, beyond the control of glycaemia, targeting the IL-1 system may also improve complications of diabetes such as cardiovascular diseases and heart failure. Indeed, the large phase 3 CANTOS study demonstrated that a single subcutaneous injection of an anti-IL-1 $\beta$ antibody every 3 months significantly lowers rate of recurrent cardiovascular events [2] and also of heart failure, especially in patients with diabetes [3]. Further, during the first 12 months of the study, IL-1 antagonism also showed a glucose-lowering effect [4]. After this period, however, anti-diabetic drugs were freely adjusted in all patients, masking the pure anti-IL-1beta effect. These results nicely confirm previous diabetes-devoted studies using IL-1 antagonists [5-10].

This article is a contribution to the special issue on Inflammation and Type 2 Diabetes - Guest Editor: Marc Y. Donath

Marc Y. Donath

Marc.Donath@usb.ch

$1 \quad$ Universitatsspital Basel, Basel, Switzerland
Beyond the potential of improving glycaemia and of preventing cardiovascular diseases, antagonizing the IL-1 system in patients with type 2 diabetes may also prevent microvascular complications, although other immune modulatory treatments may also be effective, see the comprehensive review by Mesquida et al. on diabetic eye disease [11]. Furthermore, several conditions associated with a metabolic syndrome such as rheumatoid arthritis are driven by the innate system and may benefit from targeted anti-inflammatory treatment [8]. This may be the case for the pathogenesis of polycystic ovary syndrome, as proposed in the original contribution of Popovic and co-authors [12]. Understanding the role of inflammation and of the gut microbiome in type 2 diabetes may also provide an explanation for the impressive benefit of bariatric surgery in metabolism. This is depicted in the thorough review by Debédat and colleagues [13]. A neglected but essential aspect of diabetes is its association with depressive symptoms. Herder and Hermanns convincingly provide arguments supporting a causal role of inflammatory processes in these often-devastating conditions [14]. IL-6 is a pleiotropic cytokine with multiple effects in metabolism. It is the merit of Lehrskov and Christensen to provide a clear overview on the role of IL-6 in metabolism, portraying its multiple aspects [15].

Are thus all questions answered? Clearly not, the reader will enjoy the refreshing article by Böni-Schnetzler and Meier [16] on the development of islet inflammation in type 2 diabetes, highlighting the physiology of this process, which eventually becomes deleterious. This article should also increase awareness on differences in findings on islet inflammation between humans and rodents. Also, from a molecular biology point of view, an exciting topic is the transcriptional control of macrophage polarization in type 2 diabetes; an inviting overview is presented by Drareni and colleagues [17]. Finally, and importantly, Dalmas opens the door to other immune cell populations, in particular of innate lymphoid cells, which emerge as key sentinels of metabolic tissues and privileged partners of macrophages [18]. 
Overall, it will become apparent to the reader of this special issue that whilst the role of inflammation in the development of type 2 diabetes is now well established, several exciting aspects remain to be investigated. Basic scientists should be encouraged to further investigate the multiple facets of immune regulation of metabolism in physiology and pathology, whilst clinicians are invited to explore further indications for anti-cytokine therapies in type 2 diabetes and associated conditions. Altogether, this will pave the way to the next era of immunometabolism that is a causative treatment of type 2 diabetes and complications.

\section{References}

1. Kataria Y, Ellervik C, Mandrup-Poulsen T (2019) Treatment of type 2 diabetes by targeting interleukin-1: a meta-analysis of 2921 patients. Semin Immunopathol. https://doi.org/10.1007/s00281-01900743-6

2. Ridker PM, Everett BM, Thuren T et al (2017) Antiinflammatory therapy with canakinumab for atherosclerotic disease. N Engl J Med 377:1119-1131

3. Everett BM, Cornel J, Lainscak M et al (2018) Anti-inflammatory therapy with canakinumab for the prevention of hospitalization for heart failure. In: Circulation

4. Everett BM, Donath MY, Pradhan AD, Thuren T, Pais P, Nicolau JC, Glynn RJ, Libby P, Ridker PM (2018) Anti-inflammatory therapy with canakinumab for the prevention and management of diabetes. J Am Coll Cardiol 71:2392-2401

5. Rissanen A, Howard CP, Botha J, Thuren T (2012) Effect of antiIL-1beta antibody (canakinumab) on insulin secretion rates in impaired glucose tolerance or type 2 diabetes: results of a randomized, placebo-controlled trial. Diabetes Obes Metab 14:1088-1096

6. Cavelti-Weder C, Babians-Brunner A, Keller C, Stahel MA, KurzLevin M, Zayed H, Solinger AM, Mandrup-Poulsen T, Dinarello CA, Donath MY (2012) Effects of gevokizumab on glycemia and inflammatory markers in type 2 diabetes. Diabetes Care 35:16541662

7. Sloan-Lancaster J, Abu-Raddad E, Polzer J, Miller JW, Scherer JC, de Gaetano A, Berg JK, Landschulz WH (2013) Double-blind, randomized study evaluating the glycemic and anti-inflammatory effects of subcutaneous LY2189102, a neutralizing IL-1beta antibody, in patients with type 2 diabetes. Diabetes Care 36:2239-2246

8. Ruscitti PaA, Saverio and Airò, Paolo and Battafarano, Norma and Cantarini, Luca and Cantatore, Francesco Paolo and Carlino, Giorgio and D'Abrosca, Virginia and Frassi, Micol and Frediani,
Bruno and Iacono, Daniela and Maggio, Roberta and Masedu, Francesco and Mulé, Rita and Pantano, Ilenia and Prevete, Immacolata and Sinigaglia, Luigi and Valenti, Marco and Viapiana, Ombretta and Cipriani, Paola and Giacomelli, Roberto (2018) Anti-Interleukin-1 treatment in patients with rheumatoid arthritis and type 2 diabetes (TRACK): a multicentre, randomised, open, prospective, controlled, Parallel-Group Trial. Lancet https:// ssrn.com/abstract $=3258674$

9. Donath MY (2014) Targeting inflammation in the treatment of type 2 diabetes: time to start. Nat Rev Drug Discov 13:465-476

10. Larsen CM, Faulenbach M, Vaag A, Vølund A, Ehses JA, Seifert B, Mandrup-Poulsen T, Donath MY (2007) Interleukin-1-receptor antagonist in type 2 diabetes mellitus. N Engl J Med 356:1517-1526

11. Mesquida M, Drawnel F, Fauser S (2019) The role of inflammation in diabetic eye disease. Semin Immunopathol. https://doi.org/10. 1007/s00281-019-00750-7

12. Popovic M, Sartorius G, Christ-Crain M (2019) Chronic low-grade inflammation in polycystic ovary syndrome: is there a (patho)physiological role for interleukin-1? Semin Immunopathol. https:// doi.org/10.1007/s00281-019-00737-4

13. Debédat J, Amouyal C, Aron-Wisnewsky J, Clément K (2019) Impact of bariatric surgery on type 2 diabetes: contribution of inflammation and gut microbiome? Semin Immunopathol. https:// doi.org/10.1007/s00281-019-00738-3

14. Herder C, Hermanns N (2019) Subclinical inflammation and depressive symptoms in patients with type 1 and type 2 diabetes. Semin Immunopathol. https://doi.org/10.1007/s00281-019-00730$\mathrm{x}$

15. Lehrskov LL, Christensen RH (2019) The role of interleukin-6 in glucose homeostasis and lipid metabolism. Semin Immunopathol. https://doi.org/10.1007/s00281-019-00747-2

16. Böni-Schnetzler M, Meier DT (2019) Islet inflammation in type 2 diabetes. Semin Immunopathol. https://doi.org/10.1007/s00281019-00745-4

17. Drareni K, Gautier JF, Venteclef N, Alzaid F (2019) Transcriptional control of macrophage polarisation in type 2 diabetes. Semin Immunopathol. https://doi.org/10.1007/s00281-019-00748-1

18. Dalmas E (2019) Role of innate immune cells in metabolism: from physiology to type 2 diabetes. Semin Immunopathol. https://doi. org/10.1007/s00281-019-00736-5

Publisher's note Springer Nature remains neutral with regard to jurisdictional claims in published maps and institutional affiliations. 